\title{
Risk Factors for Acquiring Scrub Typhus among Children in Deoria and Gorakhpur Districts, Uttar Pradesh, India, 2017
}

\author{
Jeromie Wesley Vivian Thangaraj, \\ Ravi Vasanthapuram, Leonard Machado, \\ Govindakarnavar Arunkumar, Samir V. Sodha, \\ Kamran Zaman, Tarun Bhatnagar, \\ Shafeeq K. Shahul Hameed, Arun Kumar, \\ Jazeel Abdulmajeed, Anoop Velayudhan, \\ Avinash Deoshatwar, Anita S. Desai, \\ K. Hemanth Kumar, Nivedita Gupta, \\ Kayla Laserson, Manoj Murhekar; \\ Scrub Typhus Risk Factor Study Group ${ }^{1}$
}

Scrub typhus is associated with outbreaks of acute encephalitis syndrome in Uttar Pradesh, India. A case-control study indicated that children residing, playing, or visiting fields; living with firewood stored indoors; handling cattle fodder; and practicing open defecation were at increased risk for scrub typhus. Communication messages should focus on changing these behaviors.

$\mathrm{O}$ utbreaks of acute encephalitis syndrome (AES) with high case-fatality rates have been reported from Gorakhpur district, Uttar Pradesh, India, for $>2$ decades. These outbreaks occur during monsoon and postmonsoon seasons and predominantly affect children. Scrub typhus (ST) accounted for about two thirds of AES cases (1-4) and is also an important etiology of acute febrile illness (AFI) in the region (5). Untreated cases of ST-attributable AFI can progress to AES.

Author affiliations: Indian Council of Medical Research National Institute of Epidemiology, Chennai, India (J.W.V. Thangaraj, T. Bhatnagar, M. Murhekar); National Institute of Mental Health and Neurosciences, Bengaluru, India (R. Vasanthapuram, S.K.S. Hameed, A.S. Desai); World Health Organization, New Delhi, India (L. Machado, A. Kumar); Manipal Centre for Virus Research, Manipal Academy of Higher Education (Deemed to be University), Manipal, India (G. Arunkumar, J. Abdulmajeed, K.H. Kumar); US Centers for Disease Control and Prevention, New Delhi (S.V. Sodha, A. Velayudhan, K. Laserson); Indian Council of Medical Research National Institute of Virology, Gorakhpur, India (K. Zaman); Indian Council of Medical Research National Institute of Virology, Pune, India (A. Deoshatwar); Indian Council of Medical Research, New Delhi (N. Gupta)
ST, caused by the bacterium Orientia tsutsugamushi, is transmitted by the bite of trombiculid mites, which live in moist soil covered with vegetation (6). Several risk factors, including certain household characteristics, work-related practices, and behaviors, have been identified among adult ST patients (7-11). Household characteristics include location of the house near a grassland, vegetable field, or ditch; presence of mud floors; piled weeds inside the house; and scrub vegetation in the vicinity (7). Work-related practices include working in vegetable fields or hilly areas and working in short sleeves or with bare hands (8). Certain behaviors such as lying on grass and squatting to defecate or urinate also are associated with ST $(8,10,11)$. Because these risk factors are region specific, we conducted an exploratory case-control study among children in Gorakhpur and Deoria districts of Uttar Pradesh to identify factors associated with ST infection.

\section{The Study}

We conducted AFI surveillance in public health facilities in Deoria $(n=5)$ and Gorakhpur $(n=3)$ districts during October 3-November 11, 2017, a period coinciding with AES outbreaks in Gorakhpur district. We enrolled children $2-15$ years of age with a $\geq 3$-day history of fever, from whom we collected $2 \mathrm{~mL}$ of blood after obtaining written informed consent from parents and assent from children 7-15 years of age. We screened serum samples for IgM and IgG against $O$. tsutugamushi by using ELISA kits (Scrub Typhus Detect; InBios International Inc., Seattle, WA, USA). For our study, an optical density value $\geq 0.5$ indicated IgM positivity. This cutoff has $93 \%$ sensitivity and $91 \%$ specificity for ST diagnosis (12). An optical density value $<0.5$ indicated IgM and IgG negativity.

Febrile children who were positive for O. tsutugamushi IgM were considered case-patients, whereas patients who were seronegative for $\operatorname{IgM}$ and $\operatorname{IgG}$ were considered controls. Case-patients and controls and their parents or guardians were interviewed in their houses by using a pretested structured questionnaire to collect information on sociodemographics, household characteristics, behaviors, and environmental exposures during the 2 weeks before fever onset. Interviewers were blinded to the case-patient or control status of children except during the first week of study. 
We calculated crude odds ratios (ORs) and 95\% CIs associated with different exposures. We included variables with $p$ value $\leq 0.2$ in univariate analysis in a stepwise backward elimination model to identify variables for inclusion in the final unconditional multiple logistic regression model by using Stata 13 (StataCorp LLC, College Station, TX, USA).

We recruited 819 AFI patients, of whom $155(18.9 \%)$ had O. tsutugamushi IgM (case-patients) and 409 (49.9\%) were seronegative (controls) (online Technical Appendix Table 1, https://wwwnc.cdc.gov/EID/article/24/12/18-0695Techapp1.pdf). We excluded 255 (31.1\%) patients who had only $O$. tsutugamushi IgG. We interviewed all case-patients and 406 controls. All case-patients and controls were from rural areas. The mean age of case-patients was higher than controls ( 7.0 vs. 6.3 years; $p=0.018$ ); $39 \%$ of case-patients and $51 \%$ controls were $\leq 5$ years of age. A higher proportion of case-patients than controls were from households that owned agricultural land ( $83 \%$ vs. $73 \% ; p=0.017)$ (Table 1$)$.

Aside from fever, clinical signs and symptoms among patients varied (online Technical Appendix Table 2). Five ST patients, who did not receive doxycycline/azithromycin, had onset of neurologic manifestations and required hospitalization; they recovered after administration of azithromycin.

Univariate analysis showed that ST patients were more likely than controls to live in houses located within or adjoining fields, houses with unpaved surroundings with mud or unkempt grass, and mud-floored houses (Table 2). In addition, a higher proportion of case-patients lived in households that used wood or cow dung for cooking and stored this fuel indoors. Compared with controls, children with ST were more likely to have played in agricultural fields, defecated in agricultural fields, bathed in a river or stream, carried grass bundles on their heads, handled fodder for cattle, or visited or accompanied parents to an agricultural field during the 2 weeks before fever onset (Table 2).
Multivariable analysis showed that children residing in houses within or adjoining fields (adjusted OR [aOR] $1.56,95 \%$ CI $1.02-2.38$ ) and that stored firewood indoors (aOR 1.61, 95\% CI 1.06-2.45) had higher odds of acquiring ST. Open defecation (aOR 2.0, 95\% CI 1.18-3.39), playing in (aOR 5.2, 95\% CI 1.92-14.2) or visiting (aOR $1.65,95 \%$ CI $1.07-2.52$ ) agricultural fields, and handling cattle fodder (aOR 2.05, 95\% CI 1.13-3.70) also were associated with ST (Table 2).

\section{Conclusions}

In Gorakhpur and Deoria districts, recent exposure to the outdoor environment, either while defecating or playing in agricultural fields, as well as visiting agricultural fields, storing firewood indoors, and handling fodder for cattle were associated with higher risk for acquiring ST among children. Of these risk factors, defecation in the agricultural field was the most common exposure at the population level. The observed association of ST and defecation in fields is consistent with the findings from an ST outbreak in Manipur, India, where persons who defecated or urinated in the jungle or bushy areas were found to be at higher risk for ST (11). In Gorakhpur and Deoria districts, about one third of the study population had toilets, a finding consistent with the 2015 national level survey, which indicated that $29.5 \%$ of the households in rural Uttar Pradesh had sanitary toilets and 27.3\% of households that had access to toilets were using them (http:// www.mdws.gov.in/sites/default/files/Swachh\%20Survekshan\%20Report\%20Eng.PDF). Efforts to prevent ST in the region therefore also need to focus on constructing household and community toilets, as well as behavior change communication about avoiding open defecation in the fields. In addition, storing firewood and fodder indoors attracts rodents that can harbor mites. Mites present on the firewood and fodder collected from fields might expose children to mite bites during storage or handling of the cattle fodder.

\begin{tabular}{|c|c|c|c|}
\hline Variables & $\%$ Case-patients, $n=155$ & $\%$ Controls, $n=406$ & $p$ value \\
\hline \multicolumn{4}{|l|}{ Age group, y } \\
\hline $2-5$ & 39 & 51 & \\
\hline $6-10$ & 46 & 35 & \\
\hline $11-15$ & 14 & 15 & \\
\hline Mean age, $y(S D)$ & $7.0(3.2)$ & $6.3(3.5)$ & 0.0176 \\
\hline \multicolumn{4}{|l|}{ Sex } \\
\hline M & 61 & 61 & \\
\hline $\mathrm{F}$ & 39 & 39 & 0.882 \\
\hline \multicolumn{4}{|l|}{ District } \\
\hline Deoria & 56 & 55 & \\
\hline Gorakhpur & 44 & 45 & \\
\hline \multicolumn{4}{|l|}{ Religion } \\
\hline Hindu & 92 & 89 & \\
\hline Other & 8 & 11 & 0.348 \\
\hline Median duration of fever, $\mathrm{d}(\mathrm{IQR})$ & $7(4.5-10.0)$ & $5(4-8)$ & \\
\hline \multicolumn{4}{|l|}{ Household owns agricultural land } \\
\hline No & 17 & 27 & \\
\hline Yes & 83 & 73 & 0.017 \\
\hline
\end{tabular}

*Values are percentages unless otherwise indicated. IQR, interquartile range. 
Table 2. Risk factors associated with scrub typhus, Gorakhpur and Deoria districts, Uttar Pradesh, 2017

\begin{tabular}{|c|c|c|c|c|c|}
\hline Risk factor & $\begin{array}{c}\% \text { Cases, } \\
\mathrm{n}=155\end{array}$ & $\begin{array}{c}\% \text { Controls, } \\
n=406\end{array}$ & OR $(95 \% \mathrm{Cl})$ & $\begin{array}{c}p \\
\text { value }\end{array}$ & $\operatorname{aOR}(95 \% \mathrm{Cl})$ \\
\hline Location of house within or adjoining field & 67 & 52 & $1.86(1.26-2.74)$ & 0.002 & $1.56(1.02-2.38)$ \\
\hline Mud or grassy approach road to house & 41 & 36 & $1.21(0.82-1.76)$ & 0.335 & \\
\hline Mud or grassy pavement in front of house & 81 & 71 & $1.73(1.09-2.74)$ & 0.018 & \\
\hline Mud house floor & 72 & 59 & $1.88(1.25-2.82)$ & 0.002 & \\
\hline Presence of waterbody within $100 \mathrm{~m}$ of house & 61 & 51 & $1.52(1.04-2.23)$ & 0.029 & \\
\hline \multicolumn{6}{|l|}{ Location of toilet } \\
\hline No toilet & 76 & 57 & $2.76(1.59-4.78)$ & 0.001 & \\
\hline Within house & 12 & 24 & 1 & & \\
\hline Outside house & 12 & 18 & $1.36(0.66-2.80)$ & & \\
\hline Wood or dung fuel & 55 & 34 & $2.32(1.59-3.39)$ & $<0.01$ & \\
\hline Storage of fuel (wood or dung) inside house or veranda & 53 & 34 & $2.16(1.48-3.14)$ & $<0.01$ & $1.61(1.06-2.45)$ \\
\hline Food waste given to cattle or disposed in common place & 30 & 25 & $1.27(0.84-1.92)$ & 0.248 & \\
\hline Spotted rats inside house, daily & 80 & 79 & $1.09(0.68-1.73)$ & 0.731 & \\
\hline Spotted rats outside house, daily & 43 & 48 & $0.81(0.56-1.17)$ & 0.263 & \\
\hline Presence of scrub vegetation around house & 79 & 73 & $1.38(0.88-2.17)$ & 0.154 & \\
\hline Storage of wet food produce inside house or veranda & 37 & 25 & $1.78(1.20-2.65)$ & 0.004 & \\
\hline Storage of dried food produce inside house or veranda & 83 & 72 & $1.87(1.17-2.99)$ & 0.009 & \\
\hline Livestock kept inside house or veranda & 32 & 22 & $1.65(1.09-2.48)$ & 0.017 & \\
\hline Fodder for livestock stored inside house or veranda & 32 & 24 & $1.49(0.99-2.24)$ & 0.055 & \\
\hline Place of drying clothes; bushes, ground, fence, or roof & 30 & 25 & $1.30(0.86-1.95)$ & 0.213 & \\
\hline Usual clothing at home for lower body; fully covered & 24 & 21 & $1.18(0.76-1.83)$ & 0.451 & \\
\hline Usual clothing at home for upper body; fully covered & 8 & 11 & $0.71(0.36-1.38)$ & 0.308 & \\
\hline Usual clothing for school for lower body; fully covered & 48 & 42 & $1.14(0.74-1.76)$ & 0.543 & \\
\hline Usual clothing for school for upper body; fully covered & 51 & 43 & $1.27(0.82-1.97)$ & 0.283 & \\
\hline Usual clothing during playing for lower body; fully covered & 21 & 17 & $1.26(0.79-1.99)$ & 0.334 & \\
\hline Usual clothing during playing for upper body; fully covered & 8 & 8 & $1.0(0.51-1.97)$ & 0.980 & \\
\hline Using clothing while sleeping for lower body; fully covered & 19 & 17 & $1.1(0.68-1.78)$ & 0.692 & \\
\hline Using clothing while sleeping for upper body; fully covered & 7 & 7 & $0.89(0.42-1.88)$ & 0.763 & \\
\hline Change of clothes before sleep; never or sometimes & 86 & 84 & $1.24(0.73-2.11)$ & 0.423 & \\
\hline Do not wear footwear during playing & 73 & 65 & $1.25(0.82-1.89)$ & 0.298 & \\
\hline Do not wear footwear while going to school & 6 & 4 & $1.37(0.59-3.19)$ & 0.465 & \\
\hline \multicolumn{6}{|l|}{ Place of play in 2 wks before illness } \\
\hline Indoor & 5 & 17 & 1 & 0.001 & \\
\hline Around house & 77 & 76 & $3.77(1.68-8.45)$ & & $2.68(1.15-6.27)$ \\
\hline Agricultural fields & 18 & 7 & $9.38(3.68-23.90)$ & & $5.20(1.92-14.15)$ \\
\hline \multicolumn{6}{|l|}{ Practice of washing after playing } \\
\hline Usually takes bath & 13 & 14 & 1 & & \\
\hline Usually washes hands or feet & 59 & 60 & $1.05(0.60-1.84)$ & 0.769 & \\
\hline None & 28 & 25 & $1.21(0.65-2.25)$ & 0.225 & \\
\hline Floor as usual place of sleeping & 14 & 11 & $1.41(0.81-2.44)$ & & \\
\hline \multicolumn{6}{|l|}{ Place of defecation in 2 wks before illness } \\
\hline Around house & 7 & 14 & $1.12(0.52-2.42)$ & 0.001 & $0.93(0.41-2.12)$ \\
\hline Field & 76 & 48 & $3.62(2.25-5.82)$ & & $2.00(1.18-3.39)$ \\
\hline Toilet & 17 & 38 & 1 & & 1 \\
\hline Early morning defecation & 30 & 25 & $1.28(0.85-1.93)$ & 0.237 & \\
\hline Swam or bathed in river or stream in 2 wks before illness & 11 & 5 & $2.37(1.21-4.67)$ & 0.012 & $1.74(0.80-3.77)$ \\
\hline Visited field in 2 wks before illness & 61 & 39 & $2.49(1.70-3.63)$ & $<0.01$ & $1.65(1.07-2.52)$ \\
\hline Carried bundle of grass over head in 2 wks before illness & 14 & 6 & $2.29(1.25-4.21)$ & $<0.01$ & $0.75(0.35-1.61)$ \\
\hline Handled cattle fodder in 2 wks before illness & 25 & 9 & $3.46(2.1-5.69)$ & $<0.01$ & $2.05(1.13-3.70)$ \\
\hline
\end{tabular}

Our study had limitations. First, although OT IgM is detectable as early as 4 days after fever onset (13), some ST patients in our study might have been negative for IgM and hence misclassified as controls. However, such nondifferential misclassification is likely to underestimate the actual association. Further, the median duration of fever was 7 days (interquartile range 4.5-10.0 days) among casepatients and 5 days (interquartile range 4-8 days) among controls (Table 1), indicating minimal possibility of such misclassification. Some controls might have been misclassified as case-patients because of persistence of IgM from previous infection (14). However, this possibility is less likely considering that IgM peaks by 4 weeks of infection and declines rapidly thereafter (15). Second, our controlpatients were AFI patients from healthcare facilities and not healthy children from the general population. Nevertheless, the behaviors of children visiting healthcare facilities before their febrile illness and children from the general population are less likely to be different.

For prevention of ST among children in Gorakhpur and Deoria districts, communication messages should focus on changing behaviors such as defecating or playing 
in agricultural fields and unnecessary visits to agricultural fields. Onset of central nervous system manifestations among untreated ST patients underscores the importance of early administration of doxycycline/azithromycin to ST patients in Gorakhpur and Deoria districts to prevent progression to AES.

Members of the Scrub Typhus Risk Factor Study Group: Vishal Shete, M. Prakash, Surya Prakash (Chennai, India); Reeta Mani, R. Vijayalakshmi, Narendra Kumar, Premanjali (Bangaluru, India); Ujjawal Sinha, Gagan Sharma, Hemant Kharnare, Abhishek Jain, Rachana Kathuria, A.K. Puttaraju, Manish K. Gawande, Ashish Tigga, Vishesh Kumar, Rajesh Badgal, Hamid Sayeed, Madhup Bajpai (New Delhi, India); Prasanth Pareet, Deepchand Agre, Nishikant Kumar (Manipal, India); Mohan Papanna, Ekta Saroha, Rajesh Yadav, Aslesh Prabhakaran (New Delhi, India); and Hirawati Deval and Gajanan Patil (Gorakhpur, India).

This study was funded by the Indian Council of Medical Research and a US Centers for Disease Control and Prevention (CDC) Cooperative Agreement for Global Health Security to the National Institute of Mental Health and Neurosciences.

The Institutional Ethics Committee of the Indian Council of Medical Research National Institute of Epidemiology approved the study protocol. The CDC Center for Global Health Associate Director for Science reviewed the protocol and determined that $\mathrm{CDC}$ was not engaged.

\section{About the Author}

Dr. Thangaraj currently works as a scientist with the Indian Council of Medical Research-National Institute of Epidemiology in Chennai, India. His primary research interests include the epidemiology of acute encephalitis syndrome.

\section{References}

1. Murhekar MV, Mittal M, Prakash JAJ, Pillai VM, Mittal M, Girish Kumar CP, et al. Acute encephalitis syndrome in Gorakhpur, Uttar Pradesh, India—role of scrub typhus. J Infect. 2016;73:6236. http://dx.doi.org/10.1016/j.jinf.2016.08.014

2. Mittal M, Thangaraj JWV, Rose W, Verghese VP, Kumar CPG, Mittal M, et al. Scrub typhus as a cause of acute encephalitis syndrome, Gorakhpur, Uttar Pradesh, India. Emerg Infect Dis. 2017;23:1414-6. http://dx.doi.org/10.3201/eid2308.170025

3. Pulla P. Disease sleuths unmask deadly encephalitis culprit. Science. 2017;357:344. http://dx.doi.org/10.1126/science.357. 6349.344
4. Mittal M, Bondre V, Murhekar M, Deval H, Rose W, Verghese VP, et al. Acute encephalitis syndrome in Gorakhpur, Uttar Pradesh, 2016: clinical and laboratory findings. Pediatr Infect Dis J. 2018;37:1101-6.

5. Vivian Thangaraj JW, Mittal M, Verghese VP, Kumar CPG, Rose W, Sabarinathan R, et al. Scrub typhus as an etiology of acute febrile illness in Gorakhpur, Uttar Pradesh, India, 2016. Am J Trop Med Hyg. 2017;97:1313-5. http://dx.doi.org/10.4269/ ajtmh.17-0135

6. Rahi M, Gupte MD, Bhargava A, Varghese GM, Arora R. DHR-ICMR Guidelines for diagnosis \& management of Rickettsial diseases in India. Indian J Med Res. 2015;141:417-22. http://dx.doi.org/10.4103/0971-5916.159279

7. Lyu Y, Tian L, Zhang L, Dou X, Wang X, Li W, et al. A casecontrol study of risk factors associated with scrub typhus infection in Beijing, China. PLoS One. 2013;8:e63668-63668. http://dx.doi.org/10.1371/journal.pone.0063668

8. Kweon S-S, Choi J-S, Lim H-S, Kim J-R, Kim K-Y, Ryu S-Y, et al. A community-based case-control study of behavioral factors associated with scrub typhus during the autumn epidemic season in South Korea. Am J Trop Med Hyg. 2009;80:442-6. http://dx.doi.org/10.4269/ajtmh.2009.80.442

9. Trowbridge P, P D, Premkumar PS, Varghese GM. Prevalence and risk factors for scrub typhus in South India. Trop Med Int Health. 2017;22:576-82. http://dx.doi.org/10.1111/tmi.12853

10. Varghese GM, Raj D, Francis MR, Sarkar R, Trowbridge P, Muliyil J. Epidemiology \& risk factors of scrub typhus in south India. Indian J Med Res. 2016;144:76-81. http://dx.doi.org/ 10.4103/0971-5916.193292

11. Singh SI, Devi KP, Tilotama R, Ningombam S, Gopalkrishna Y, Singh TB, et al. An outbreak of scrub typhus in Bishnupur district of Manipur, India, 2007. Trop Doct. 2010;40:169-70. http://dx.doi.org/10.1258/td.2010.090468

12. Blacksell SD, Tanganuchitcharnchai A, Nawtaisong P, Kantipong P, Laongnualpanich A, Day NPJ, et al. Diagnostic accuracy of the InBios Scrub Typhus Detect enzyme-linked immunoassay for the detection of IgM antibodies in Northern Thailand. Clin Vaccine Immunol. 2015;23:148-54. http://dx.doi.org/10.1128/CVI.00553-15

13. Ching WM, Wang H, Eamsila C, Kelly DJ, Dasch GA. Expression and refolding of truncated recombinant major outer membrane protein antigen (r56) of Orientia tsutsugamushi and its use in enzyme-linked immunosorbent assays. Clin Diagn Lab Immunol. 1998;5:519-26.

14. Varghese GM, Rajagopal VM, Trowbridge P, Purushothaman D, Martin SJ. Kinetics of IgM and IgG antibodies after scrub typhus infection and the clinical implications. Int J Infect Dis. 2018;71:535. http://dx.doi.org/10.1016/j.ijid.2018.03.018

15. Kim DM, Lee Y-M, Back J-H, Yang TY, Lee JH, Song H-J, et al. A serosurvey of Orientia tsutsugamushi from patients with scrub typhus. Clin Microbiol Infect. 2010;16:447-51. http://dx.doi.org/10.1111/j.1469-0691.2009.02865.x

Address for correspondence: Kayla Laserson, US Centers for Disease Control and Prevention, American Embassy, Shantipath, Chanakyapuri, New Delhi 110021, India; email: klaserson@cdc.gov 